\title{
Psychrophilic dry anaerobic digestion of cow dung for methane production: Effect of inoculum
}

\author{
Gefu Zhu ${ }^{\mathrm{a}, *}$, Ajay Kumar Jha ${ }^{\mathrm{b}, \mathrm{c}}$ \\ a Key Lab of Urban Environment and Health, Institute of Urban Environment, Chinese Academy of Sciences, \\ Xiamen 361021, China \\ b State Key Laboratory of Urban Water Resource and Environment, \\ School of Municipal and Environmental Engineering, Harbin Institute of Technology, Harbin 150090, China \\ c Kathmandu Engineering College, Tribhuvan University, Kathmandu, Nepal
}

*Corresponding author, e-mail: gfzhu@iue.ac.cn

Received 5 Jan 2012

Accepted 9 Aug 2012

\begin{abstract}
Stabilizing organic solid wastes economically is a challenge, particularly in cold and hilly regions where the temperature can be below $20^{\circ} \mathrm{C}$. Inocula sampled from psychrophilic and mesophilic environments were introduced and their effects on psychrophilic dry anaerobic digestion of cow dung for methane production at $15{ }^{\circ} \mathrm{C}$ were investigated in single-stage batch reactors for 84 days. The results showed that the specific methane yield and volatile-solid removal in the fermentation system inoculated with psychrotroph flora had been enhanced by $28.3 \%$ and $28.6 \%$, respectively, compared to a system inoculated with mesophilic flora. Furthermore, the start up and performance of the process had been improved. The specific methane yield was greatest when the psychrophilic dry anaerobic fermentation process was inoculated with a weight of $50 \%$ of the substrate, among the systems with psychrophilic inocula of $30 \%, 50 \%$, and $70 \%$.
\end{abstract}

KEYWORDS: psychrophilic temperature, dry fermentation process, biogas, organic materials removal

\section{INTRODUCTION}

Anaerobic digestion is an effective waste-stabilization method treating bio-wastes by microbial consortia in an oxygen-free environment to recover potential renewable energy with nutrient-rich organic fertilizer for sustainable waste management. Until recently however, the majority of the full-scale applications and research efforts have been concentrated on wet anaerobic digestion within the mesophilic or thermophilic temperature ranges ${ }^{1-3}$. This was mostly due to the conviction that psychrophilic anaerobic digestion $\left(<20^{\circ} \mathrm{C}\right)$ was not feasible because of low microbial activity and biogas production rates under temperate conditions ${ }^{4}$. However, some research ${ }^{4,5}$ presented that psychrophilic anaerobic digesters can successfully degrade organic matters for reasonable biogas production. The anaerobic fermentation of swine manure with HRT 100 days at low ambient temperature produced $0.03-0.09 \mathrm{~m}^{3}$ of biogas per cubic meter of digester ${ }^{6}$. Similarly, another previous study ${ }^{7}$ reported that $0.66-0.92 \mathrm{~m}^{3} \mathrm{~m}^{-2}$ day $^{-1}$ of biogas (70\% methane) was collected at $10-11^{\circ} \mathrm{C}$ from a lagoon with 50 days HRT in California. Moreover, the psychrophilic wet anaerobic digestion was reported stable and as efficient as mesophilic or thermophilic wet anaerobic digestion process ${ }^{8}$. A reduction in pathogenic micro organisms by psychrophilic anaerobic digestion was also observed ${ }^{9}$. There is, however, no report on psychrophilic dry anaerobic digestion process.

The lower rate of hydrolysis and decrease in the population, growth, and activity of microbial consortia increase the solids-retention time twice to thrice, compared to the mesophilic anaerobic digestion and process instability ${ }^{10}$. Considering that most parts of the world have low-ambient temperatures and waste generation is a natural consequence of human life, wastes are mostly discharged at low-temperature. Besides, disposal of the wastes in cold and hilly regions is a serious problem because un-decomposed waste causes health and environment impacts including aesthetic nuisance, organic pollution, uncontrolled methane emission, and various water-borne diseases. Solid wastes need to be stabilized in their produced form or with limited water as water is hard to collect in the hilly regions of the developing world due to lack of infrastructure.

Even though such wastes contain high amount of biodegradable compounds, it is a great challenge to treat the wastes economically because a significant amount of energy is required to bring the bioreactor 
temperature up to the mesophilic range ${ }^{11}$. Inoculum quality and its percentages are regarded as one of the main factors for start up and stability of the ultimate psychrophilic fermentation process. Previous research ${ }^{12}$ reported that no methane is produced from fresh manure in batch digestion systems within a fivemonth period without inoculation at 5,10 , and $15^{\circ} \mathrm{C}$. Methane production at these low temperatures is possible when high inoculation percentages are applied. It is clear that the first start-up should be carried out with inoculation material adapted as much as possible to the digestion conditions. However, such inoculation material is hardly ever available. The purpose of this work was to assess the effects of mesophilic and psychrophilic inocula and various amounts of psychrophilic inocula on biogas production and removal of organic matters from undiluted cow dung in batch assays.

\section{MATERIALS AND METHODS}

\section{Experimental set up and procedure}

The experiments were carried out in four batch labreactors of 2.51 effective volume with an internal diameter of $13 \mathrm{~cm}$, and height of $25 \mathrm{~cm}$. The capped reactors were kept in a water bath of operational temperature $15 \pm 1^{\circ} \mathrm{C}$. The temperature of the water bath was maintained by continuous circulating of refrigerated water from a water-cooling machine (DTY15A, Beijing Detianyou Technology Development Co. Ltd.). The temperature of the refrigerator was set up at $15^{\circ} \mathrm{C}$. Each reactor was fitted with four ports, two on the cover and two on the side. One of the cover ports was used for measuring biogas production. The sample for analysis of biogas quality was also drawn from the same port. The other cover port was set aside as spare. One of the side ports was kept above $5 \mathrm{~cm}$ above from the bottom. This port was used to take out the sample for the analysis of various parameters while a $\mathrm{pH}$ meter was set up at the other side port. The samples were stored at $-4{ }^{\circ} \mathrm{C}$ in a freezer before analysis. The analysis was generally performed within one week.

\section{Characteristics of inoculum and feedstocks}

The digested manure from the mesophilic anaerobic digestion of cow dung was taken as inoculum for the reactor $\mathrm{R} 1$. The temperature of the mesophilic inoculum was decreased from $35 \pm 1^{\circ} \mathrm{C}$ to $15 \pm 1^{\circ} \mathrm{C}$ into different steps so that mesophilic anaerobes can adapt to low temperature. These steps are presented in Table 1. The digested slurry from the reactor R1 was named as psychrophilic inoculum in this study
Table 1 Steps for decreasing the temperature of mesophilic inoculant.

\begin{tabular}{lcc}
\hline Step & Temperature $\left({ }^{\circ} \mathrm{C}\right)$ & Time $(\mathrm{d})$ \\
\hline I & $30 \pm 1$ & 7 \\
II & $25 \pm 1$ & 7 \\
III & $20 \pm 1$ & 14 \\
IV & $15 \pm 1$ & 14 \\
\hline
\end{tabular}

and used as inoculum for the reactors R2, R3, and R4. The feedstocks of the digesters, R1-R4, were inoculated with 30\% mesophilic, and 30\%, 50\%, and $70 \%$ psychrophilic inocula, respectively, on wetweight basis. The cow dung was mixed with proper amount of inoculum manually.

The cow dung was obtained from a livestock farm of Harbin, China. In the fermentation process, the substrates were pretreated and fed into airtight digesters under specified environmental conditions for 84 days without dilution. Pretreatment consisted in separating the cow dung from foreign materials like stones, woods, metals, and other inorganic materials, and the addition of inoculants into the feedstocks. The visible straw and feathers were removed manually. No other nutrients, chemicals or water was fed into the reactors. The average values of the characteristics of the manures and inoculants for each reactor are shown in Table 2. The C:N of the manure was found adequate (25:10) because it is often suggested that the $\mathrm{C}: \mathrm{N}$ ratio in the substrate should be in between 20:1-30:1. The high proportion of volatile solid (VS) to total solid (TS) $(84.8 \%)$ depicts that a large fraction of the cow dung was biodegradable and could serve as an important feedstock for biogas production. Table 3 shows the composition of the substrates and inoculants in each reactor and the mean values of their physical-chemical characteristics. Each digester was purged with nitrogen for 15-20 min to create complete anaerobic environment. The contents of the reactors were slowly shaken once daily for 2-3 min to create a homogeneous substrate and to prevent stratification and formation of a surface crust and distributing microorganisms throughout the digester.

\section{Analytical methods}

The physico-chemical parameters analysed were temperature, $\mathrm{pH}$, TS, VS, chemical oxygen demand (COD), soluble chemical oxygen demand (SCOD), volatile fatty acids (VFAs), total phosphorus, total Kjeldahl nitrogen, ammonia nitrogen, and free ammonia. All the analytical determinations were performed according to standard methods ${ }^{13}$. The $\mathrm{pH}$ of 
Table 2 Characteristics of substrates and inoculants.

\begin{tabular}{|c|c|c|c|c|c|}
\hline Type of analysis & $\mathrm{CM}^{(1)}$ & $\mathrm{CM}^{(2)}$ & Inoc. $^{(1,35)}$ & Inoc. $^{(1,15)}$ & Inoc. $^{(2)}$ \\
\hline $\mathrm{pH}$ & 7.68 & 7.30 & 7.76 & 7.83 & 7.54 \\
\hline Total solid (g/kg) & 15.79 & 17.69 & 10.22 & 9.84 & 10.45 \\
\hline Volatile solids ( $\%$ of TS) & 84.88 & 84.84 & 68.22 & 63.28 & 74.10 \\
\hline Chemical oxygen demand (g/l) & 150.54 & 163.63 & 74.53 & 69.11 & 87.97 \\
\hline Soluble COD (g/l) & 63.89 & 66.96 & 22.36 & 18.96 & 23.51 \\
\hline Total organic carbon (g/l) & 41.37 & 43.15 & 14.31 & 13.12 & 17.35 \\
\hline Total phosphorus $(\mathrm{g} / \mathrm{l})$ & 1.53 & 1.60 & 1.35 & 1.40 & 1.35 \\
\hline Total Kjeldahl Nitrogen (g-N/l) & 2.70 & 2.84 & 2.33 & 2.39 & 2.40 \\
\hline Ammonia nitrogen $(\mathrm{g}-\mathrm{N} / \mathrm{l})$ & 1.48 & 1.55 & 1.28 & 1.32 & 1.39 \\
\hline
\end{tabular}

CM: cow manure; $\mathrm{CM}^{(1)}$ : Feedstock for R1; $\mathrm{CM}^{(2)}$ : Feedstock for R2; Inoc. ${ }^{(1,35)}$ : Mesophilic inoculant at $35^{\circ} \mathrm{C}$; Inoc. ${ }^{(1,15)}$ : Mesophilic inoculant brought at $15^{\circ} \mathrm{C}$ for R1; Inoc. ${ }^{(2)}$ : Psychrophilic inoculant for R2, R3, and R4.

Table 3 Composition and condition of the reactors.

\begin{tabular}{lcclcccc}
\hline Reactor & Cow dung $(\mathrm{g})$ & Inoculant $(\mathrm{g})$ & Type of inoculant & Temp. $\left({ }^{\circ} \mathrm{C}\right)$ & $\mathrm{pH}$ & $\mathrm{TS}(\%)$ & VS $(\%$ TS $)$ \\
\hline R1 & 1000 & 300 & Mesophilic & $15 \pm 1$ & 7.75 & $14.7 \pm 0.3$ & $84.2 \pm 0.2$ \\
R2 & 1000 & 300 & Psychrophilic & $15 \pm 1$ & 7.38 & $14.4 \pm 0.2$ & $83.8 \pm 0.2$ \\
R3 & 1000 & 500 & Psychrophilic & $15 \pm 1$ & 7.41 & $13.5 \pm 0.3$ & $83.4 \pm 0.2$ \\
R4 & 1000 & 700 & Psychrophilic & $15 \pm 1$ & 7.49 & $13.1 \pm 0.3$ & $82.8 \pm 0.2$ \\
\hline
\end{tabular}

the mixtures was measured with a digital $\mathrm{pH}$ meter (Seven Multi SK40, Switzerland). The free ammonia was calculated using the previously reported formulae ${ }^{14}$. The yielded biogas was measured per day by downward water displacement method at atmospheric pressure using calibrated 1 or 21 cylindrical jar for each reactor. The constituents $\left(\mathrm{CH}_{4}, \mathrm{CO}_{2}\right.$, and $\left.\mathrm{H}_{2}\right)$ of the biogas were determined using gas chromatography (SP-6800A, Shandong Lunan Instrument Factory, China) equipped with a thermal conductivity detector and a $2 \mathrm{~m}$ stainless column packed with Porapak TDS201 (60-80 mesh). Nitrogen was employed as the carrier gas at a flow rate of $40 \mathrm{ml} / \mathrm{min}$. The operation temperature for the injection port, oven, and detector was $80^{\circ} \mathrm{C}$. The cumulative methane production for each test was determined by summing daily methane production, which was calculated by timing daily biogas production with corresponding methane content minus the methane produced due to inoculum source. The samples taken from the batch cultures were centrifuged at $3100 \mathrm{~g}$ for $15 \mathrm{~min}$, and then acidified with $\mathrm{HCl}$ and filtered through a $0.2 \mu \mathrm{m}$ membrane for the analysis of VFAs and ethanol. The concentrations of the VFAs and ethanol were determined using a second gas chromatograph (SP6890, Shandong Lunan Instrument Factory, China) equipped with a flame ionization detector and a $2 \mathrm{~m}$ stainless ( $5 \mathrm{~mm}$ inside diameter) column packed with Porapak GDX-103 (60/80 mesh). The operational temperatures of the injection port, the column, and the detector were 220,190 , and $220^{\circ} \mathrm{C}$, respectively. Nitrogen was used as carrier gas at a flow rate of $50 \mathrm{ml} / \mathrm{min}$.

\section{Microbial community analysis}

Genomic DNA of the sludge samples was extracted using a DNA extraction Kit (MO Bio Laboratories, Inc., Carlsbad, CA, USA) following the manufacturer's instructions. Extracted DNA was dissolved in $60 \mu \mathrm{l} 1 \times \mathrm{TE}$ buffer solution. The V3 and V4 regions of $16 \mathrm{~S}$ rRNA were amplified by PCR using universal bacterial primers $\left(341 \mathrm{~F}, 5^{\prime}\right.$-CCTACGGGAGGCAGCAG-3' with a GC clamp and 907R, 5'-CCGTCAATTCMTTTGAGTTT-3') and universal archaeal primers $\left(344 \mathrm{~F}, 5^{\prime}\right.$-ACGGGGYGCAGCAGGCGCGA-3' with a GC clamp and 915R, 5'-GTGCTCCCCCGCCAATTCCT- $3^{\prime}$ ). The PCR amplification was conducted in a $50 \mu \mathrm{l}$ system containing $5 \mu \mathrm{l}$ $10 \times$ Ex Taq buffer, $4 \mu \mathrm{l}$ dNTP mixture $(2.50 \mathrm{mM})$, $1 \mu \mathrm{l}$ forward primer $(20 \mu \mathrm{M}), 1 \mu \mathrm{l}$ reverse primer $(20 \mu \mathrm{M}), 2.5$ ng DNA template, and 0.15 U Ex Taq DNA polymerase (Takara, Dalian, China), using a thermal cycler (model 9700; ABI, Foster, CA, USA), started with an initial denaturation of DNA for $10 \mathrm{~min}$ at $94{ }^{\circ} \mathrm{C}$, followed by 30 cycles for $1 \mathrm{~min}$ at $94^{\circ} \mathrm{C}, 30 \mathrm{~s}$ at $55^{\circ} \mathrm{C}$ (decreasing by $0.10^{\circ} \mathrm{C}$ per cycle to $52^{\circ} \mathrm{C}$ ), and $1 \mathrm{~min}$ at $72^{\circ} \mathrm{C}$; final extension was $10 \mathrm{~min}$ at $72^{\circ} \mathrm{C}$. The PCR products were separated using the 
Dcode universal mutation detection system (Biorad Laboratories, Hercules, CA, USA). Polyacrylamide gels with $40-60 \%$ vertical denaturing gradient were prepared. Then, $10 \mu \mathrm{l}$ PCR products were loaded and electrophoresed at $120 \mathrm{~V}$ and $60^{\circ} \mathrm{C}$ for $10 \mathrm{~h}$. Gels were stained with silver as described in the previous research ${ }^{15}$. All DGGE bands were excised and dissolved in $30 \mu \mathrm{l} 1 \times \mathrm{TE}$ at $40^{\circ} \mathrm{C}$ for $3 \mathrm{~h}$, and then centrifuged at $12400 \mathrm{~g}$ for $3 \mathrm{~min}$. The $3 \mu \mathrm{l}$ supernatant was used as the template and PCR amplification was conducted under the conditions as above described using the same primers. The PCR products were purified by Gel Extraction Mini Kit (Watson Biotechnologies Inc., China) and ligated into pMD18$\mathrm{T}$ vector (Takara, Dalian, China), and then cloned into E. coli DH5 $\alpha$. Some white clones from each sample were randomly selected for PCR analysis, and positive clones were selected for sequencing by ABI3730, and partial 16s rRNA gene sequences were analysed using the BLAST program ${ }^{16}$ in GenBank.

\section{RESULTS AND DISCUSSION}

\section{Evolution of pH, ammonia nitrogen and VFAs}

Fig. 1 depicts the $\mathrm{pH}$, ammonia nitrogen, and free ammonia variation patterns in all the functional reactors during the digestion period. The $\mathrm{pH}$ of feedstock for R1 was initially 7.68 while that of feedstock for R2, $\mathrm{R} 3$, and R4 was 7.30. It decreased to $6.87,6.85,6.82$, and 6.79 in $28,28,14$, and 14 days after the beginning of the digestion process for the reactors R1-R4, respectively (Fig. 1a). It happened due to the increase in VFAs production by acidogenic bacteria during the start up phase of each experiment. The easily digestible fraction of organic matter was hydrolysed and converted to fatty acids during a start up period. The $\mathrm{pH}$ value did not drop off much lower because the substrates were able to buffer themselves and prevent acidification, due to proper alkalinity of the manure to maintain optimal biological activity and stability of the anaerobic digestion system. The $\mathrm{pH}$ value for all the experiments began to rise gradually as the VFAs were consumed by methanogens and transferred to the methane. The $\mathrm{pH}$ range noted seemed favourable for anaerobic digestion process. In addition, there was no apparent effect on $\mathrm{pH}$ due to variation in percentage of inoculum as the observed trend of $\mathrm{pH}$ variation was identical in each operating reactor.

The initial ammonia nitrogen of feedstock for R 1 was initially $1.48 \mathrm{~g}-\mathrm{N} / \mathrm{l}$ while that of feedstock for $\mathrm{R} 2$, R3, and R4 was $1.55 \mathrm{~g}-\mathrm{N} / \mathrm{l}$. In this study, average ammonia nitrogen concentration was increased to some extent in all the reactors during the start
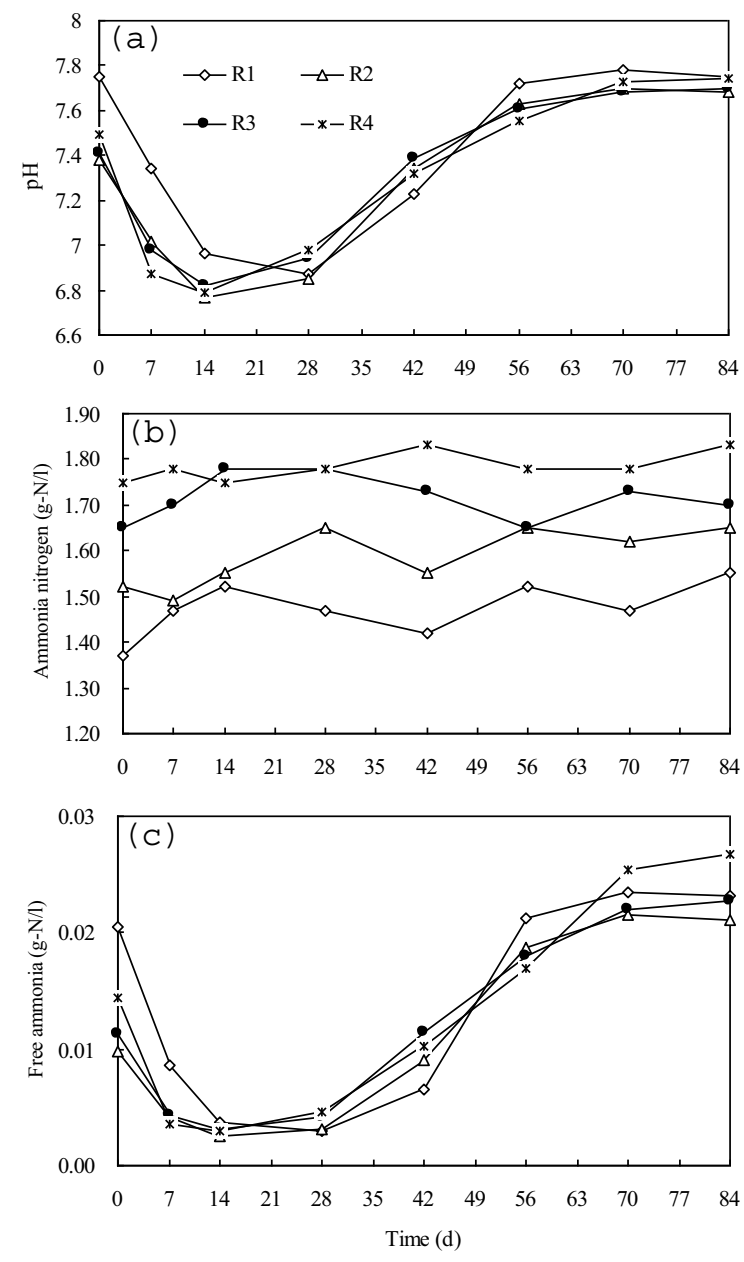

Fig. 1 Variation pattern of (a) $\mathrm{pH}$, (b) ammonia nitrogen, and (c) free ammonia during the digestion period.

up period. Additional ammonia nitrogen was produced due to hydrolysis of amino acids and proteins. Afterwards, the concentration of ammonia nitrogen decreased since it was used as nitrogen source for methanogens growth. It increased again since the protein-containing hard biodegradable fraction began to hydrolyse some days after the beginning of the digestion process. As a result, fluctuated ammonia nitrogen variation patterns were observed for all the tests during the digestion period (Fig. 1b). The ammonia nitrogen values obtained were not supposed to be high enough to create inhibition because, although nitrogen can inhibit anaerobic digestion, the ammonia nitrogen concentration that can be tolerated was relatively high. The concentration of $2.80 \mathrm{~g}-\mathrm{N} / 1$ has been reported as critical value for ammonia nitrogen inhibition in the anaerobic digestion process ${ }^{17}$. The ammonia concentrations were noted much lower than 

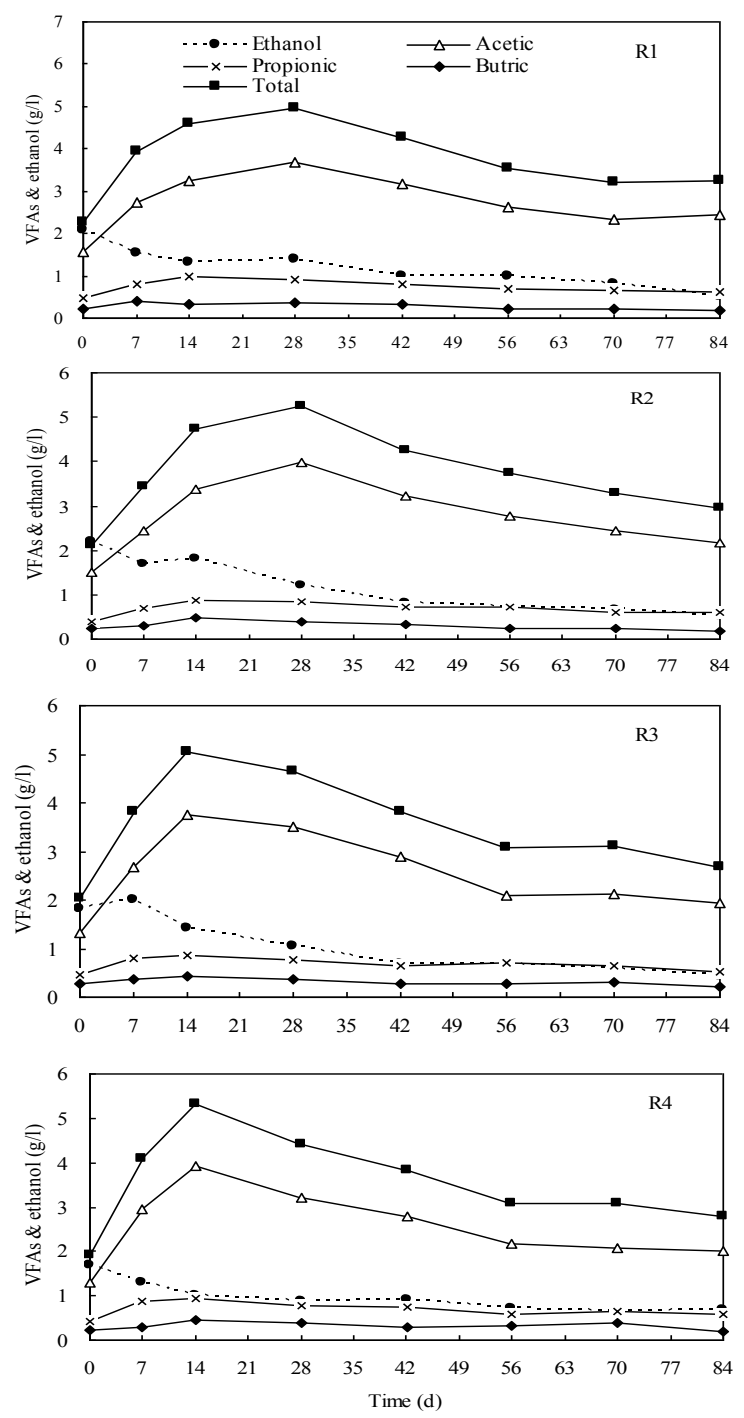

Fig. 2 Accumulation and consumption of VFAs and ethanol during the digestion period.

the above inhibition value. In addition, free ammonia is considered more inhibitive component. However, an inhibitive threshold of $1.1 \mathrm{~g}-\mathrm{N} / \mathrm{l}$ of free ammonia was reported ${ }^{18}$. The free ammonia levels for all the reactors (Fig. 1c) during the digestion period were remained much lower than the inhibitive levels reported $^{18}$.

Fig. 2 depicts VFAs and ethanol accumulation and consumption in all the functional reactors during the digestion period. VFAs are usually produced due to the degradation of the complex organic polymers during hydrolysis and acidogenic stages. The hydrolysis is considered as a rate limiting step in

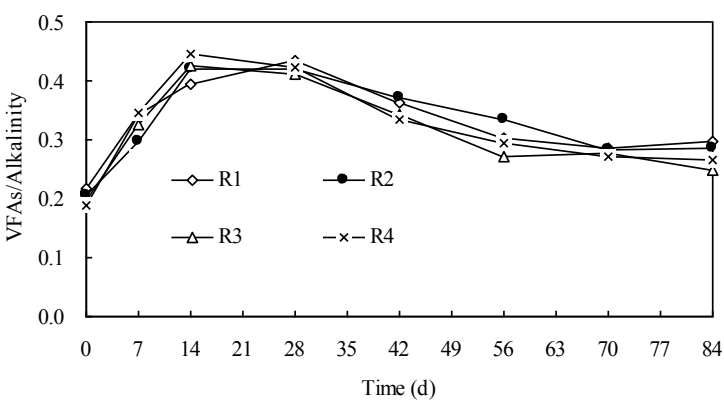

Fig. 3 VFAs to alkalinity ratio during the digestion period.

anaerobic digestion process and the rate of hydrolysis becomes slower at lower temperature due to decrease in microbial activities under psychrophilic conditions $^{2}$. Hence the production of VFAs was slow in all the reactors compared to our previous experiments for mesophilic and thermophilic dry anaerobic fermentation processes of cow dung ${ }^{19,20}$. They were relatively high in the reactor R3 and R4 followed by $\mathrm{R} 2$ and $\mathrm{R} 1$. The VFAs increased gradually to a higher concentration. The principal volatile acids formed were acetic, butyric, and propionic acids. Acetic acid was the dominant volatile fatty acid. At low temperatures, $\mathrm{H}_{2} / \mathrm{CO}_{2}$ was converted into acetate and methane is then formed from the acetate ${ }^{21}$. The share of propionic and butyric acids was observed low. The residual VFAs were observed higher in R1 followed by R2, R4, and R3. This result suggested that methanogenic activities have been increased with the use of psychrophilic inoculum and its percentages up to $50 \%$. The propionic acid was not degraded significantly even the percentages of inoculum had been increased.

VFAs and alkalinity together are the good indicators for evaluating the process stability of the anaerobic reactor. Fig. 3 shows the variation in VFAs to alkalinity ratio during the digestion period. The ratio varied between 0.2 and 0.5 and so the process seemed stable because the anaerobic digestion is not notably inhibited if the VFAs to alkalinity ratios are below $0.8^{22}$. No accumulation of VFA and no drastic fall in $\mathrm{pH}$ also support the notion that the process was not inhibited extensively.

\section{Biogas yields and methane content}

Fig. 4 shows the daily biogas yield, percentage methane content, and cumulative methane production in the operational reactors $\mathrm{R} 1-\mathrm{R} 4$ during the digestion period. In this study, the bioreactors with psychrophilic inoculum displayed a relatively rapid 

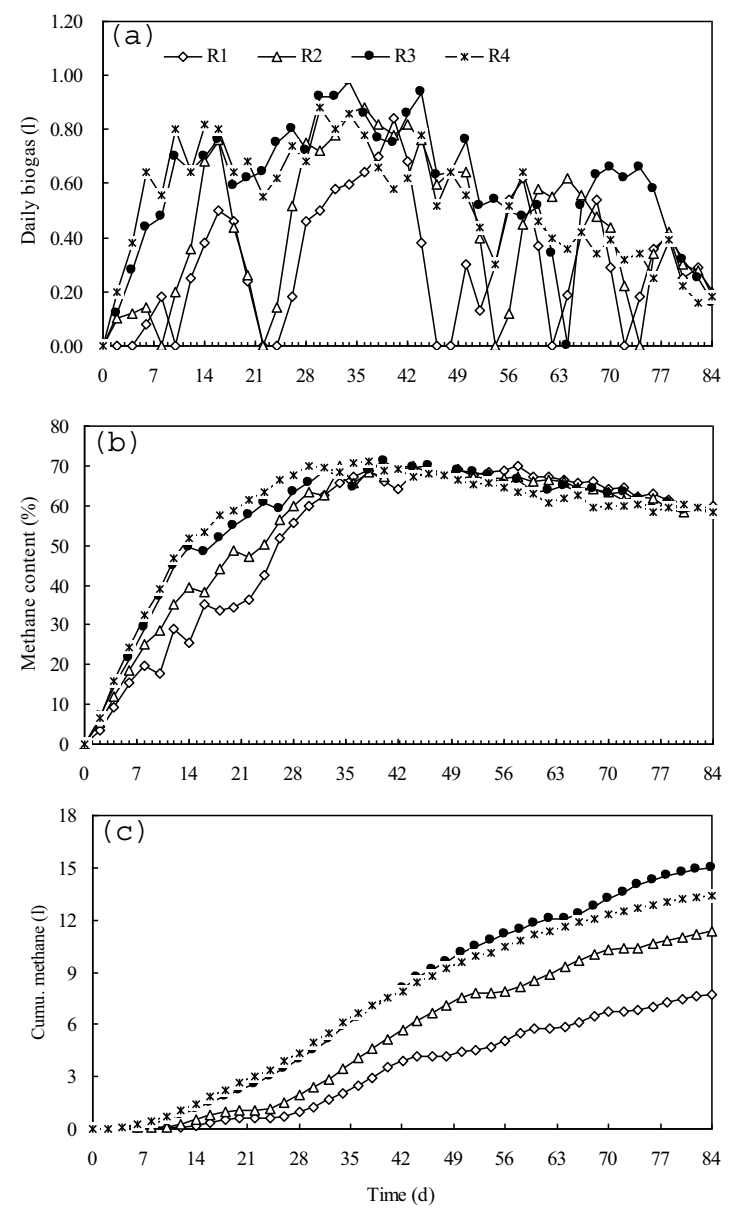

Fig. 4 Biogas and methane yields during the digestion period: (a) daily biogas, (b) methane content, and (c) cumulative methane.

start up and higher biogas yields than the reactor with mesophilic inoculum due to the inability of mesophilic bacterial biomass producing gas to survive under low temperature conditions. It can also be concluded that microbes could not adapt low temperature in short time and adaptation rate is increasing with the time. The temperature adapted inoculum can relatively enhance the start up process and digestion operation as it may contain psychrophiles and mesophilic bacteria acclimatized on psychrophilic temperatures. The most rapid start up was observed in the reactor with the highest amount of inoculum. Hence, an increment in the amount of inoculum could considerably boost microorganism activity and ultimately treatment efficiency during start-up phase. This finding is consistent with the previous research for wet anaerobic digestion at low temperature ${ }^{12}$.

In the present study, similar trends of daily biogas and methane yields were observed for all the tests. The biogas generation was started after seeding, kept increasing until reaching the peak, and then began to decline but two or more peaks were observed during the digestion period. The initial biogas production was due to readily biodegradable organic matter in the substrates and presence of methanogens in the inoculum material. The peak values for the reactors $\mathrm{R} 1-\mathrm{R} 4$ were 0.431 biogas with 0.281 methane on the 40th day, 0.461 biogas with 0.301 methane on day 36, 0.521 biogas with 0.341 methane on day 34, and 0.511 biogas with 0.331 methane on day 32 . The cumulative biogas generation of the reactors R1, R2, R3, and R4 measured were 13.02, 18.73, 24.98, and $22.561 / \mathrm{kg}$ with $7.72,11.31,14.99$, and $13.401 / \mathrm{kg}$ methane contents, respectively. The biogas yields decreased $(<1 \%$ of cumulative biogas yield $)$ at the end of experiments on 84 days. The highest amount of biogas and methane yields was noted in R3, followed by R4, R2, and R1. The increment of inoculum failed to produce higher quantity of biogas as bioreactor with higher amount of inoculum contained more inorganic carbon and subsequently increase the size of the digester. The methane content was determined low during start up period and increased gradually in all the functional reactors. The average and highest methane contents were determined $59.3 \%, 69.2 \%$; $60.4 \%, 69.9 \%$; $60.0 \%, 70.1 \%$; and $59.4 \%, 71.1 \%$ in the reactors R1-R4, respectively. There were no significant variations in the methane content among different treatments. The initial methane contents in the yielded biogas has increased and attained highest rapidly in $\mathrm{R} 4$ followed by $\mathrm{R} 3, \mathrm{R} 2$, and $\mathrm{R} 1$. The percentage of $\mathrm{CO}_{2}$ has increased and stabilized in between 15 and 30\%; which is lower than mesophilic and thermophilic anaerobic digestion processes ${ }^{19,20}$. Similar results were observed in treating slaughterhouse wastewater at 20,25 , and $30^{\circ} \mathrm{C}^{23}$ and swine manure at 10,15 , and $20^{\circ} \mathrm{C}^{24}$. As in mesophilic and thermophilic anaerobic fermentation processes ${ }^{19,20}$, hydrogen gas was detected in very small percentage $(<1 \%)$ during start up phase and then decreased. Negligible percentage $(<0.30 \%)$ of hydrogen gas was usually detected during the rest of the digestion period in all the tests. This might have happened as all the available hydrogen gas rapidly combined with $\mathrm{CO}_{2}$ to produce acetate, which was then converted into methane.

\section{Organic materials removal efficiency}

In an anaerobic digestion process, the organic content of the waste is reduced concomitantly with production of biogas. The efficiency of dry anaerobic digestion 
Table 4 Organic matter degradation and methane yields.

\begin{tabular}{|c|c|c|c|c|c|c|c|c|}
\hline \multirow[t]{2}{*}{$\mathrm{R}$} & \multicolumn{6}{|c|}{ Organic matter \& its removal } & \multicolumn{2}{|c|}{ Methane yield } \\
\hline & $\mathrm{VS}_{\mathrm{i}}(\mathrm{g} / \mathrm{kg})$ & $\mathrm{VS}_{\mathrm{r}}(\%)$ & $\mathrm{COD}_{\mathrm{i}}(\mathrm{g} / \mathrm{l})$ & $\mathrm{COD}_{\mathrm{r}}(\%)$ & $\operatorname{SCOD}_{\mathrm{i}}(\mathrm{g} / \mathrm{l})$ & $\operatorname{SCOD}_{\mathrm{r}}(\%)$ & $1 \mathrm{CH}_{4} / \mathrm{g} \mathrm{VS}_{\mathrm{r}}$ & $1 \mathrm{CH}_{4} / \mathrm{g} \mathrm{COD}_{\mathrm{r}}$ \\
\hline $\mathrm{R} 1$ & 123.71 & 19.93 & 139.26 & 22.05 & 55.25 & 57.56 & 0.116 & 0.100 \\
\hline $\mathrm{R} 2$ & 118.78 & 25.63 & 134.75 & 26.72 & 52.67 & 61.84 & 0.148 & 0.129 \\
\hline $\mathrm{R} 3$ & 112.69 & 30.83 & 125.41 & 31.15 & 49.65 & 64.09 & 0.174 & 0.156 \\
\hline R4 & 108.18 & 28.32 & 119.65 & 28.41 & 45.68 & 63.31 & 0.160 & 0.142 \\
\hline
\end{tabular}

$\mathrm{R}$ : reactors, i: initial, r: removal.
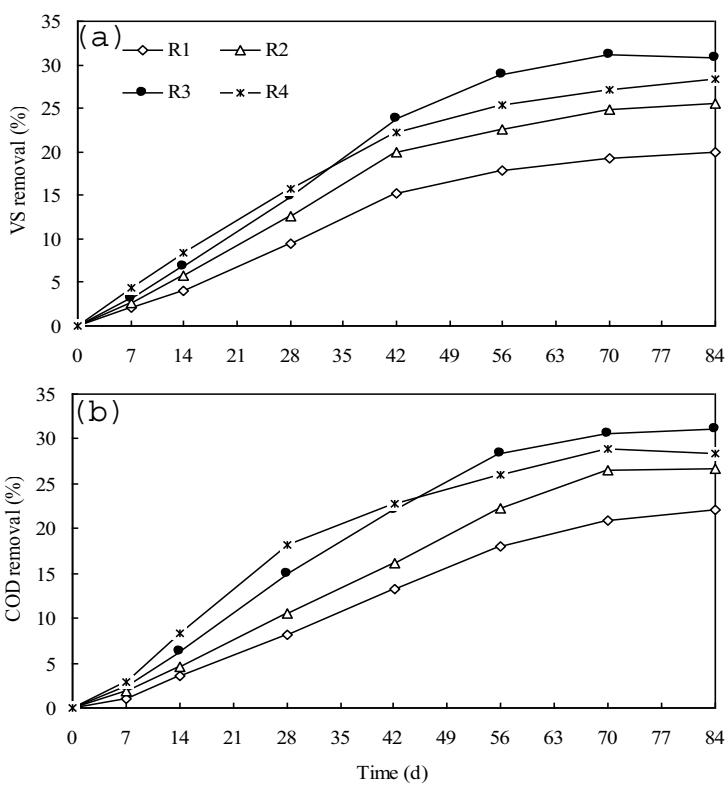

Fig. 5 Organic materials removal efficiency during the digestion period (a) VS and (b) COD.

was evaluated in terms of biological conversion of the substrates with VS and COD removals. Fig. 5 presents the VS and COD removal efficiency for all the treatments during the digestion period. The values of VS and COD were high in the beginning and gradually decreased due to consumption by fermenting and methanogenic bacteria. Table 4 presents the organic material removal efficiency and methane yield per $\mathrm{gVS}_{\mathrm{r}}$ and $\mathrm{gCOD}_{\mathrm{r}}$ in bio-methanization processes of cow dung at psychrophilic temperature. The VS removal efficiency was found greater in R3 (30.8\%) followed by R4 (28.3\%), R2 (25.6\%), and R1 (19.9\%). It means that the same amount of the psychrophilic inoculum could increase VS removal efficiency by $28.6 \%$ compared to mesophilic inoculum. The increment in inoculum amounts by $50 \%$ and $70 \%$ based on wet-basis could boost additional VS loss for energy recovery by $20.3 \%$ and $10.5 \%$, respectively. Similar trend for COD removal efficiency was found and reactor with 50\% psychrophilic inoculum obtained highest COD removal efficiency. The specific methane generation was found to be $0.116,0.148,0.174$, and $0.1601 \mathrm{CH}_{4} / \mathrm{g} \mathrm{VS}_{\mathrm{r}}$ in the functional digesters R1-R4 while in terms of $1 \mathrm{CH}_{4} / \mathrm{g} \mathrm{COD}_{\mathrm{r}}$ were $0.10,0.129$, 0.156 , and 0.142 , respectively. The result is consistent with other studies ${ }^{5,6,12}$ stating that anaerobic digestion is feasible with acceptable methane yield at low temperatures. It can be observed that the highest methane yield and organic material removal were found in R3 compared to the other treatments. Thus the methane yield can be improved by using cold adapted inoculum. Higher amount of inoculum could improve the performance and biodegradability of the substrates but an excessive amount may fail to enhance linearly due to high loading and presence of more non-carbon matters.

\section{Digestate characteristics and its reuse}

The mass balance for batch reactors reveals that the digestate contained high amounts of organic materials in all the treatments of psychrophilic anaerobic digestion compared to mesophilic and thermophilic anaerobic digestion processes ${ }^{19,20}$. This occurred because the organic material removal efficiency was found comparatively lower, in between 19.9 and $30.8 \%$ in terms of VS. It means the psychrophilic-leachate is more harmful if it flows to water source. The psychrophilic dry anaerobic digestion process results in a lower outcome of leachate and produces digested residual with lower liquid content. The digestate is useful as soil conditioner because the manure is a significant source of organic plant nutrients, which are also conserved in psychrophilic dry anaerobic digestion process. The amount of nutrients, mainly nitrogen (2.36-3.14 g-N/l), and phosphorus (1.32-1.81 g/l), were found in the digestate. Bio-fertilizers, which enrich soil and increase crop productivity with no detrimental effects on the environment, are more costeffective and eco-friendly supplements than chemical fertilizers. As the total solid for the dry digesters in 


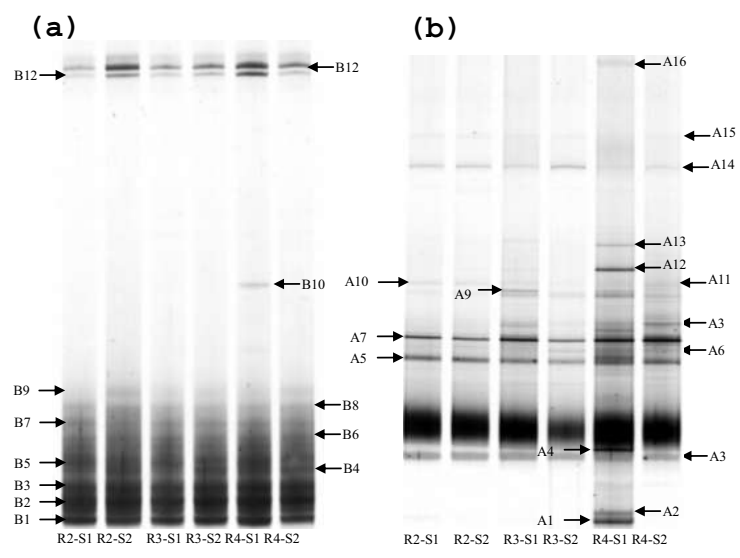

Fig. 6 DGGE fingerprint of the samples of psychrophilic dry digestion of cow dung (a) bacteria and (b) archaea; (R) reactor, (S1) sample of the 35th day, (S2) digestate.

this study was in between 10.0 and $11.6 \%$, handling of the digestate to the farms is convenient and economical.

\section{Analysis of microbial community}

The structures of the dominant bacteria and archaea in the slurry sample were analysed by PCR-DGGE finger printing. The sludge was sampled for PCRDGGE analysis on day 35 and at the end of the digestion process (on day 8 ). Twelve detected prominent bands were obtained in the bacterial DGGE profile (Fig. 6a), and then sequenced. Five of the bacterial sequences were assigned to Firmicutes, three of the sequences were clustered to Bacteroidetes, and one to Proteobacteria, Ruminobacillus, and Euryarchaeota, respectively (Table 5). Most of microbial communities such as Clostridiaceae bacterium, Lactobacillus coleohominis, and Prevotella were mesophilic bacteria, acclimated at psychrophilic temperature. It means that mesophilic bacteria could adapt to low temperature and the adaptation rate was increased with the digestion time. The presence of some bacteria which are isolated at low temperature such as Clostridium ghonii strain indicated that psychrophilic microbes also played significant role in the process of organic matter degradation at low temperature.

There were sixteen prominent bands obtained in the archaeal DGGE profile (Fig. 6b). More importantly, in all the digesters, Euryarchaeota comprised the dominant archaeal populations followed by uncultured Crenarchaeota (Table 6). All the Euryarchaeota had known methanogens as the closest relatives and belonged to the class Methanomicrobia, confirming their potential involvement in methanogenesis in the digestion process. The Crenarchaeota, however, only had close relatives of uncultured clones lacking detailed physiological characterization. Phylogenetic analysis of the representative clone sequences indicates considerable similarities in the bacterial and archaeal community compositions. The results show that both mesophilic and psychrophilic species could co-exist under low temperature digestion process. Although mesophilic species are active at psychrophilic temperatures, however, their affinity for substrate decreases with temperature. This appears to be due to increasing viscosity of cell membrane lipids, reducing the effectiveness of substrate transport during metabolism to a minimum temperature at which the membrane effectively solidifies. The cell membranes of psychrophilic organisms generally contain more unsaturated lipids, which retain fluidity at lower temperatures. The lipid composition of the cell membrane is resistant to change, so that adaptation of species to temperature is limited.

\section{Comparison of psychrophilic dry anaerobic digestion with dry mesophilic and thermophilic anaerobic digestions}

Table 7 discloses the performance characteristics of psychrophilic anaerobic treatment of undiluted cow dung compared to mesophilic and thermophilic dry anaerobic digestions. The specific methane yield in psychrophilic dry anaerobic digestion of cow dung was observed lower than mesophilic (91\%) and thermophilic $(102 \%)$ dry anaerobic digestion processes because methanogenesis is particularly sensitive to temperature and biomass activity was substantially more affected when the temperature was lowered. Low temperature has a deleterious effect on methanogenesis leading to decreased biogas production. Under psychrophilic conditions, chemical and biological reactions proceed much slower than under mesophilic and thermophilic conditions ${ }^{23,24}$ because most reactions in the biodegradation of organic matter require more energy to proceed at low temperatures ${ }^{4}$. As the organic material removal efficiency is close to methane yield, VS and COD removal efficiency at low temperature anaerobic digestion was also noted lower than that of mesophilic and thermophilic anaerobic digestions (Table 7). It means that considering mass balance, the psychrophilic digestate contained higher organic materials than the mesophilic and thermophilic digestates. In addition, the total VFAs at the end of the treatment was found higher in psychrophilic treatment than mesophilic and thermophilic digestions. In contrast, the methane content in the biogas, yielded from the psychrophilic digesters was 
Table 5 Bacterial 16S rRNA gene clones, compared by BLAST with NCBI.

\begin{tabular}{llllc}
\hline Taxonomy & Band & Accession no. & Closest sequence & Identity \\
\hline Firmicutes & B2 & AB298753 & Clostridiaceae bacterium SK061 gene & $93 \%$ \\
& B4 & JN048963 & Clostridium ghonii strain 2447.6 & $99 \%$ \\
& B7 & NR029239 & Clostridium chartatabidum strain 163 & $99 \%$ \\
& B11 & AY305322 & Butyrate-producing bacterium SR1/5 & $99 \%$ \\
Bacteroidetes & B12 & AB425925 & Lactobacillus coleohominis gene & $99 \%$ \\
& B3 & DQ168658 & Porphyromonadaceae bacterium JN18.A107.G & $99 \%$ \\
& B5 & GU112991 & Rikenellaceae bacterium 4-1-11 & $97 \%$ \\
Proteobacteria & B6 & AB477014 & Prevotella dentasini gene & $93 \%$ \\
Ruminobacillus & B8 & BY158021 & Prevotella sp. RS2 & $93 \%$ \\
Bacteria & B1 & DF471233 & Alcaligenes sp. BBTR16 & $99 \%$ \\
\hline
\end{tabular}

Table 6 Archaeal 16S rRNA gene clones, compared by BLAST with NCBI.

\begin{tabular}{llllc}
\hline Taxonomy & Band & Accession no. & Closest sequence & Identity \\
\hline Crenarchaeote & A1 & FJ618835 & Uncultured archaeon clone AM14 & $90 \%$ \\
& A2 & HM638339 & Uncultured archaeon clone LSW145m02 & $89 \%$ \\
& A3 & AY887080 & Uncultured crenarchaeote clone FSt4a & $88 \%$ \\
& A14 & AP011757 & Uncultured prokaryote & $86 \%$ \\
Euryarchaeota & A15 & JN853770 & Uncultured crenarchaeote clone KS17.19 & $89 \%$ \\
& A16 & JN853747 & Uncultured crenarchaeote clone KS17.2a & $88 \%$ \\
& A4 & DQ135988 & Methanobrevibacter sp. 1Y & $99 \%$ \\
& A5 & JQ268021 & Methanimicrococcus blatticola & $88 \%$ \\
& A6 & JQ268009 & Methanosarcina mazei strain PY-15 & $99 \%$ \\
& A7 & NR028242 & Methanosaeta concilii Opfikon & $99 \%$ \\
& A8 & BX950229 & Methanococcus maripaludis & $96 \%$ \\
& A9 & CP000867 & Methanococcus maripaludis C6 & $94 \%$ \\
& A10 & CP000867 & Methanococcus maripaludis C6 & $92 \%$ \\
& A11 & CP002565 & Methanosaeta concilii GP-6 & $99 \%$ \\
& A12 & AY196683 & Methanospirillum hungatei & $95 \%$ \\
& A13 & AB065298 & Methanoculleus bourgensis gene & $97 \%$ \\
\hline
\end{tabular}

Table 7 Comparison of performance characteristics of dry psychrophilic treatment of cow dung with dry mesophilic and thermophilic digestions ${ }^{19,20}$.

\begin{tabular}{lcccl}
\hline Parameters & Psychrophilic $^{\dagger}$ & Mesophilic $^{\ddagger}$ & Thermophilic $^{\ddagger}$ & Comparison \\
\hline Methane yield $\left(\mathrm{CH}_{4} / \mathrm{g} \mathrm{VS}_{\mathrm{r}}\right)$ & 0.174 & 0.333 & 0.351 & Lower in psychrophilic \\
Average Methane (\%) & 60.0 & 57.0 & 57.2 & Higher in psychrophilic \\
Highest methane (\%) & 70.9 & 60.4 & 61.1 & Higher in psychrophilic \\
VS removal efficiency (\%) & 30.8 & 50.0 & 53.4 & $\begin{array}{l}\text { Higher in mesophilic by } 62.3 \% \\
\text { and in thermophilic by } 73.4 \%\end{array}$ \\
COD removal efficiency (\%) & 31.2 & 55.0 & 58.4 & $\begin{array}{l}\text { Higher in mesophilic by } 76.3 \% \\
\text { and in thermophilic by } 87.2 \%\end{array}$ \\
Highest free ammonia (g-N/l) & 23 & 80 & 230 & Lower in psychrophilic \\
Total VFAs at end of experiment $(\mathrm{g} / \mathrm{l})$ & 2.7 & 1.9 & 1.5 & Higher in psychrophilic \\
\hline
\end{tabular}

Digestion period: 84 days and inoculum: $50 \%$ psychrophilic.

Digestion period: 63 days and inoculum: $20 \%$. 
found superior (70.9\%) than mesophilic $(60.4 \%)$ and thermophilic $(61.1 \%)$ anaerobic digestions because (i) reduced hydrolysis of complex organics at lower temperature have decreased acidogenesis and thus lowered the proportion of $\mathrm{CO}_{2}$ in the biogas and (ii) additional production of acetate from $\mathrm{CO}_{2}$ and $\mathrm{H}_{2}$ by homoacetogens ${ }^{25}$ and the reduction of the resulting acetate would increase the proportion of methane in the biogas. Most importantly, psychrophilic anaerobic systems are particularly growing for manure and other solid organic wastes treatment because of lower free ammonia concentrations than in the mesophilic or thermophilic process.

\section{CONCLUSIONS}

Psychrophilic dry anaerobic digestion has the potential to become an economical and easy-to-use process to treat cow dung for methane production at lowambient temperatures with the use of cold adapted inoculum. The anaerobic system inoculated with the psychrophilic inoculum could provide higher methane yield and organic material removal than the system inoculated with the mesophilic inoculum. Most of detected microbial communities such as Clostridiaceae bacterium, Lactobacillus coleohominis, and Prevotella were mesophilic bacteria, acclimated at psychrophilic temperature, indicating that mesophilic bacteria could adapt the low temperature and the adaptation rate was increased with the digestion time. An increment in amount of the psychrophilic inoculum considerably boosted the digestion efficiency and consequently resulted in the enhancement of the methane yield and organic materials removal efficiency but its larger mass failed to produce higher quantity of biogas. The performance of the bioreactor with 50\% psychrophilic inoculum (w/w) was found superior than $30 \%$ and $70 \%$ psychrophilic inocula. Compared to mesophilic and thermophilic dry fermentations, psychrophilic dry fermentation produced lower biogas and methane yields, and organic material removal efficiency but higher methane content was detected in the biogas yielded from low temperature anaerobic digestion of cow dung.

Acknowledgements: The authors thank the Knowledge Innovation Program of the Chinese Academy of Sciences (Grant No. KZCX2-EW-402-02), Ningbo Natural Science Foundation of China (Grant No. 2013A 610177), the key project of Fujian Provincial Science \& Technology program (Grant No. 2012Y0069), and the National Natural Science Foundation of China (Contract No. 21276248, 50808152) for their support for this study.

\section{REFERENCES}

1. Connaughton S, Collins G, O'Flaherty V (2006) Psychrophilic and mesophilic anaerobic digestion of brewery effluent: A comparative study. Water Res 40, 2503-10.

2. Dhaked RK, Singh P, Singh L (2010) Biomethanation under psychrophilic conditions. Waste Manag 30, 2490-6.

3. Jha AK, Li J, Nies L, Zhang L (2011) Research advances in dry anaerobic digestion process of solid organic wastes. Afr J Biotechnol 10, 14242-53.

4. Lettinga G, Rebac S, Zeeman G (2001) Challenge of psychrophilic anaerobic wastewater treatment. Trends Biotechnol 19, 363-70.

5. Wellinger A, Kaufmann R (1982) Psychrophilic methane generating from pig manure. Process Biochem 17, 26-30.

6. Rieradevall J, Ruera A, Postils L, Vicente M (1983) Low-cost anaerobic digestion of pig manure at psychrophilic temperatures. Bioenviron Syst 4, 137-54.

7. Chandler JA, Hermes SK, Smith KD (1983) A low cost $75 \mathrm{~kW}$ covered lagoon biogas system. In: Proceedings on Energy from Biomass and Wastes. St. Joseph (Michigan, USA): American Society of Agricultural Engineering.

8. Yu H, Gu G (1996) Biomethanation of brewery wastewater using an anaerobic upflow blanket filter. J Cleaner Prod 4, 219-23.

9. Côté C, Massé DI, Quessy S (2006) Reduction of indicator and pathogenic microorganisms by psychrophilic anaerobic digestion in swine slurries. Bioresour Tech 97, 686-91.

10. Jha AK, Li J, Bhattarai N, Ai B, Liu C (2011) Biomethanation of organic waste under psychrophilic conditions. In: Proceedings of the Third International Conference on Addressing Climate Change for Sustainable Development through Up-scaling Renewable Energy Technologies, October 12-14, Kathmandu, Nepal, pp 151-5.

11. Kashyap DR, Dadhich KS, Sharma SK (2003) Biomethanation under psychrophilic conditions: a review. Bioresour Tech 87, 147-53.

12. Zeeman G, Sutter K, Vens T, Koster M, Wellinger A (1988) Psychrophilic digestion of dairy cattle and pig manure: Start-up procedures of batch, fed-batch and CSTR-type digesters. Biol Waste 26, 15-31.

13. American Public Health Association (1995) Standard Methods for the Examination of Water and Wastewater, 19th edn, APHA, Washington, DC.

14. Østergaard N (1985) Biogasproduktion i det thermofile temperaturinterval. STUB rapport nr. 21. Kemiteknik. Dansk Teknologisk Institut, Taastrup (in Danish).

15. Bassam BJ, Caetano-Anollés G, Gresshoff PM (1991) Fast and sensitive silver staining of DNA in polyacrylamide gels. Anal Biochem 196, 80-3.

16. Altschul SF, Gish W, Miller W, Myers EW, Lipman DJ 
(1990) Basic local alignment search tool. J Mol Biol 215, 403-10.

17. Poggi-Varaldo HM, Rodríguez-Vázquez R, FernándezVillagómez G, Esparza-García F (1997) Inhibition of mesophilic solid-substrate anaerobic digestion by ammonia nitrogen. Appl Microbiol Biotechnol 47, 284-91.

18. Hansen KH, Angelidaki I, Ahring BK (1998) Anaerobic digestion of swine manure: inhibition by ammonia. Water Res 32, 5-12.

19. Li J, Jha AK, He J, Ban Q, Chang S, Wang P (2011) Assessment of the effects of dry anaerobic co-digestion of cow dung with waste water sludge on biogas yield and biodegradability. Int J Phys Sci 6, 3723-32.

20. Jha AK, He J, Li J, Zheng G (2010) Effect of substrate concentration on methane fermentation of cattle dung. In: Proceedings of the International Conference on Challenges in Environmental Science and Computer Engineering. Wuhan, China. March 6-7. Part 1: pp 512-5.

21. Kotsyurbenko OR, Friedrich MW, Simankova MV, Nozhevnikova AN, Golyshin PN, Timmis KN, Conrad R (2007) Shift from acetoclastic to $\mathrm{H}_{2}$-dependent methanogenesis in a West Siberian Peat Bog at low $\mathrm{pH}$ values and isolation of an acidophilic methanobacterium strain. Appl Environ Microbiol 73, 2344-8.

22. Zhao HW, Viraraghavan T (2004) Analysis of the performance of an anaerobic digestion system at the Rigna wastewater treatment plant. Bioresour Tech 95, 301-7.

23. Massé DI, Masse L, Croteau F (2003) The effect of temperature fluctuations on psychrophilic anaerobic sequencing batch reactors treating swine manure. Bioresour Tech 89, 57-62.

24. Kotsyurbenko OR, Nozhevnikova AN, Zavarzin GA (1993) Methanogenic degradation of organic matter by anaerobic bacteria at low temperature. Chemosphere 27, 1745-61.

25. Massé DI, Masse L (2000) The effect of temperature on slaughterhouse wastewater treatment in anaerobic sequencing batch reactors. Bioresour Tech 76, 91-8. 